This item was submitted to Loughborough's Research Repository by the author.

Items in Figshare are protected by copyright, with all rights reserved, unless otherwise indicated.

\title{
Development of a process control strategy for the serum-free microcarrier expansion of human mesenchymal stem cells towards cost-effective and commercially viable manufacturing
}

\section{PLEASE CITE THE PUBLISHED VERSION}

https://doi.org/10.1016/j.bej.2018.10.018

\section{PUBLISHER}

(C) Elsevier

\section{VERSION}

AM (Accepted Manuscript)

\section{PUBLISHER STATEMENT}

This paper was accepted for publication in the journal Biochemical Engineering Journal and the definitive published version is available at https://doi.org/10.1016/j.bej.2018.10.018

\section{LICENCE}

CC BY-NC-ND 4.0

\section{REPOSITORY RECORD}

Heathman, Thomas R.J., Alvin W. Nienow, Qasim A. Rafiq, Karen Coopman, Bo Kara, and Christopher J. Hewitt. 2019. "Development of a Process Control Strategy for the Serum-free Microcarrier Expansion of Human Mesenchymal Stem Cells Towards Cost-effective and Commercially Viable Manufacturing". figshare. https://hdl.handle.net/2134/37132. 


\section{Developing a process control strategy for the serum-free microcarrier expansion of human}

mesenchymal stem cells towards cost-effective and commercially viable manufacturing

\section{Thomas R.J. Heathman}

Hitachi Chemical Advanced Therapeutic Solutions (HCATS), 4 Pearl Court, Allendale, NJ, 07401

Centre for Biological Engineering, Loughborough University, Leicestershire, LE11 3TU, UK

\section{Alvin W. Nienow}

Centre for Biological Engineering, Loughborough University, Leicestershire, LE11 3TU, UK

Centre for Bioprocess Engineering, University of Birmingham, B15 2TT, UK

\section{Qasim A. Rafiq}

Advanced Centre for Biochemical Engineering, Department of Biochemical Engineering, University

College London, London, WC1E 6BT, United Kingdom

Aston Medical Research Institute, School of Life and Health Sciences, Aston University, Aston Triangle, Birmingham, B4 7ET

Centre for Biological Engineering, Loughborough University, Leicestershire, LE11 3TU, UK

Karen Coopman

Centre for Biological Engineering, Loughborough University, Leicestershire, LE11 3TU, UK

Bo Kara

FUJIFILM Diosynth Biotechnologies, Billingham, TS23 1LH, UK

\section{Christopher J. Hewitt,}

School of Life and Health Sciences, Aston University, Aston Triangle, Birmingham, B4 7ET

Centre for Biological Engineering, Loughborough University, Leicestershire, LE11 3TU, UK

\section{Author for correspondence:}

Professor Christopher J. Hewitt, Aston Medical Research Institute, School of Life and Health Sciences, Aston University, Aston Triangle, Birmingham, B4 7ET. Email: c.j.hewitt@aston.ac.uk, Tel: +44 (0) 121 2044949 


\section{Abstract}

Human Mesenchymal Stem Cells (hMSCs) are advancing through clinical development with the first allogeneic adult hMSC therapy receiving approval in Europe. To enable successful large-scale manufacture of hMSC therapies, key factors must be addressed, including an increase in product consistency and yield, and a reduction in batch-to-batch variation. This paper addresses ways to reduce variation by controlling the processing conditions, in particular the dissolved oxygen concentration $\left(\mathrm{dO}_{2}\right)$, and the selection of culture medium. Bone marrow derived hMSCs (BM-hMSC 1 and BM-hMSC 2) were grown in T-flasks and used to inoculate DASGIP DASbox bioreactors, culturing the BM-hMSCs on Plastic P-102L microcarriers in FBS-containing and serum free (SFM, PRIME-XV MSC) at various $\mathrm{dO}_{2}$ values from $100 \%$ to $10 \%$ and then harvesting cells in-situ. During the entire culture process, including medium exchange, the BM-hMSCs experienced the same $\mathrm{dO}_{2}$ value. Firstly, it was demonstrated that unless great care was taken, culture at $\mathrm{dO}_{2}$ values of $<100 \%$ could lead to wide fluctuations in the actual $\mathrm{dO}_{2}$ experienced by the $\mathrm{BM}$-hMSCs. Here, the superior control of $\mathrm{pH}$ and $\mathrm{dO}_{2}$ in the bioreactor led to improved performances compared to those in poorly controlled spinner flasks, particularly at reduced $\mathrm{dO}_{2}$ concentrations. At $25 \% \mathrm{dO}_{2}$, there was a $300 \%$ increase in the $\mathrm{BM}$-hMSC yield in the bioreactor across the two donors BM-hMSCs in SFM compared to FBS-containing medium. Overall, the process yield increased by an average of around $500 \%$ for both donors under controlled conditions in SFM at $25 \% \mathrm{dO}_{2}$ in the bioreactor compared to the poorly controlled expansion at atmospheric conditions in FBS-containing medium in spinner flasks. Process control significantly reduced the BMhMSC inter- and intra-donor variation in yield in FBS-containing medium from $79.1 \%$ in spinner flasks to $37.5 \%$ in the bioreactor, with a further reduction in controlled SFM bioreactor culture to $<15 \%$.

\section{Keywords}

Process control, serum-free, human mesenchymal stem cell, microcarrier expansion, harvest, dissolved oxygen, regenerative medicine 


\section{Introduction}

Bone marrow-derived human mesenchymal stem cells (BM-hMSCs) have generated much interest in the field of regenerative medicine (RM), with the potential to treat and in some cases, cure human disease. This interest has been largely driven by their ability to proliferate under appropriate culture conditions and their capacity to secrete a range of trophic factors which regulate host immune response and initiate tissue repair [1]. Consequently, hMSCs are advancing through clinical development targeting indications such as cardiac repair, neurological disease and immune disorders [2]. This progress is exemplified by the first allogeneic adult mesenchymal stem cell therapy to receive central marketing authorization approval in Europe [3].

The addition of microcarriers has been used to culture adherent cells such as BM-hMSCs in suspension [4] allowing for process scale-up, where online monitoring and control systems can be used to deliver a consistent and cost-effective BM-hMSC therapy. Further to this, stirred-suspension bioreactors are currently employed in biopharmaceutical production and therefore their design and operation are well-understood [5], with the potential to meet the expected manufacturing demands of large-scale BM-hMSC therapies [6]. The use of serum-free medium with microcarriers for the expansion of BMhMSCs has previously been demonstrated for uncontrolled processes [7-9] and therefore represents a viable alternative for large-scale serum free manufacture of BM-hMSCs.

One of the key aspects of a successful manufacturing process is in the reduction of product variation, which is particularly challenging when the cell is the final product. Variation can be introduced into the product by both the process input material and the process conditions [10]. The input to the process must be controlled by strict BM-hMSC isolation techniques and potentially cell selection steps to improve product input consistency [11], although appropriate isolation methods re typically poorly defined for BM-hMSCs. The US Food and Drug Administration (FDA) has released guidance documents on the use of process control and real time release testing for pharmaceutical manufacturing [12]. This 
guidance has highlighted the importance regulators are placing on continual manufacturing process improvement and enhanced understanding as a fundamental aspect of manufacturing development and control. Process analytical technology or PAT is a system for analyzing and controlling manufacturing processes through measurement of product attributes to ensure final product quality, proposed by the FDA [13]. It will therefore be desirable to utilize these PAT technologies and measure online parameters in order to develop control systems to ensure that the product characteristics remain consistent. These relevant process parameters are likely to include a combination of cell growth, medium temperature, $\mathrm{pH}, \mathrm{pO}_{2}$ and $p \mathrm{CO}_{2}$, which are commonplace in current biopharmaceutical production processes [14].

Of these parameters, the level of $\mathrm{dO}_{2}$ is the one that is usually of most concern when cultivating cells in bioreactors [15]. With respect to BM-hMSCs, our earliest work conducted in an oxygen-controlled incubator for both monolayer [16] and spinner flask culture [17] indicated that with the same donor cells as cultured here, the performance with respect to growth kinetics was better at $100 \% \mathrm{dO}_{2}$ than at lower values when cultured over 3 passages. Whilst some researchers have also shown $100 \% \mathrm{dO}_{2}$ gives enhanced growth kinetics, others have found that lower $\mathrm{dO}_{2}$ values [17] are advantageous. Much of that early literature, including our own studies, did not offer very close control of $\mathrm{dO}_{2}$ in the actual medium in which the cells are growing. Therefore, it was hypothesized that this rather loose control might account for the literature differences, always recognizing too that it might be associated with cell to cell variability. However, very tight $\mathrm{dO}_{2}$ control can be achieved by an in-situ $\mathrm{dO}_{2}$ probe throughout the culture in the closed environment offered by a bioreactor. Therefore, it was decided to investigate the effect of $\mathrm{dO}_{2}$ on culture as a major part of this study.

Thus, whilst the impact of $\mathrm{dO}_{2}$ is a major feature, the overall aim is to develop a process control strategy for the microcarrier culture of BM-hMSCs in suspension to drive increased consistency and yield into the process. The impact of this process control strategy on process economics and product consistency 
will also be assessed here for two BM-hMSC donors in both FBS-based and serum-free medium and compared to previously developed, loosely controlled monolayer and microcarrier-based suspension BM-hMSC expansion processes [8]. Of course, agitation intensity and aeration strategy (sparged, with or without protective surfactants, or headspace) are also relevant and these aspects have also been addressed for the same cells elsewhere [18].

\section{Materials \& Methods}

\subsection{Monolayer Culture}

BM-hMSCs were isolated from bone-marrow aspirate purchased from Lonza (Walkersville, USA) obtained from two healthy donors with informed consent; BM-hMSC 1 (lot: 071313B) and BM-hMSC 2 (lot: 071281D). The local Ethical Committee approved the use of the sample for research. Cells from

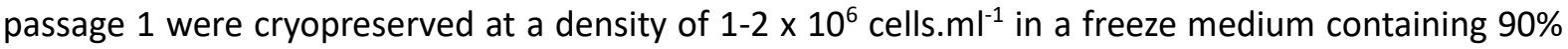
(v/v) FBS (Hyclone, Belgium) and 10\% (v/v) dimethylsulphoxide (Sigma-Aldrich, UK). Prior to the experimental work, cells were grown in T-flasks seeded at 5,000 cells.cm ${ }^{-2}$ at $37^{\circ} \mathrm{C}$ in humidified air ( $100 \%$ dissolved oxygen, $\mathrm{dO}_{2}$ ) containing $5 \% \mathrm{CO}_{2}$. For serum-free culture, the growth surface of T-flasks was coated with $0.4 \mu \mathrm{g} . \mathrm{cm}^{-2}$ PRIME-XV human fibronectin (FN) (Irvine Scientific, USA) and cultured in PRIME-XV MSC Expansion SFM (Irvine Scientific, USA) as per manufacturer's instructions. On passage, the hMSCs were washed with phosphate buffered saline without $\mathrm{Ca}^{+}$or $\mathrm{Mg}^{+}(\mathrm{PBS})$ and incubated for 4 min with TrypLE Express (Invitrogen, UK). Dissociation reagents were inactivated by the addition of appropriate growth medium and the cell suspension was centrifuged at $220 \mathrm{~g}$ for $5 \mathrm{~min}$. The supernatant was discarded, and the remaining pellet was re-suspended in an appropriate volume of culture medium. BM-hMSCs underwent one adaptation passage in serum-free medium, prior to experimental work taking place.

\subsection{DASGIP DASbox bioreactor microcarrier culture}


The glass surfaces of $250 \mathrm{ml}$ DASGIP DASbox bioreactors (diam. T = $60 \mathrm{~mm}$ ) (Eppendorf, Germany) were siliconized with Sigmacoat (Sigma-Aldrich, UK) according to manufacturer's instructions. The bioreactors were equipped with a 3 -blade $30^{\circ}$-pitch, down pumping impeller (diameter, $D=30.25$ $\mathrm{mm})$, a temperature probe, a Hamilton $\mathrm{dO}_{2}$ probe, a Hamilton $\mathrm{pH}$ probe, an off-gas analyser and two sterile sample ports. Solid, non-porous Plastic P-102L microcarriers of 160-200 microns (Solohill, USA) were prepared at 500 or $1000 \mathrm{~cm}^{2}$ following manufacturer's instructions. Microcarriers were or coated with $0.1 \mu \mathrm{g} . \mathrm{cm}^{-2}$ PRIME-XV FN prior to hMSC inoculation at 6,000 cells. $\mathrm{cm}^{-2}$ and cultured in $100 \mathrm{~mL}$ of either Dulbecco's Modified Eagle Medium (DMEM; Lonza, UK) supplemented with $10 \%$ (v/v) foetal bovine serum (FBS) (Lot: RVC35874, Hyclone, Belgium) and $2 \mathrm{mM}$ ultraglutamine (Lonza, UK), or PRIME-XV MSC Expansion SFM with bioreactor control set-points of $37^{\circ} \mathrm{C}$ and $\mathrm{pH} 7.4$. As discussed earlier, various dissolved oxygen concentrations $\left(\mathrm{dO}_{2}\right)$ were used as set out in detail below. A $50 \%$ medium exchange was performed every two days as per manufacturer's instructions, with fresh culture medium equilibrated to the appropriate $\mathrm{dO}_{2}$, temperature and $\mathrm{pH}$ using a controlled bioreactor vessel on the DASGIP system prior to medium exchange. Following inoculation, the culture was static for one hour, after which the culture was agitated constantly at the minimum rate for just complete suspension of microcarriers ( $N_{J s}$ ) found to be $115 \mathrm{rpm}$ as recommended previously $[2,3,4]$, with daily medium and cell-microcarrier samples of $1 \mathrm{~mL}$ taken for analysis. The DASbox system was set up, calibrated and controlled using the DASGIP DASbox control unit (Eppendorf, Germany) and was operated with headspace aeration to achieve sufficient gas supply.

\subsection{DASGIP DASbox bioreactor harvest}

BM-hMSCs were harvested using a method previously developed by us $[19,20]$. Briefly, the DASbox control was switched off and the microcarriers allowed to settle. The spent culture medium was removed and the microcarriers were washed twice in $50 \mathrm{ml}$ of $\mathrm{Ca}^{2+}$ and $\mathrm{Mg}^{2+}$ free PBS. The PBS was removed before adding $80 \mathrm{~mL}$ of TrypLE Express dissociation reagent for 10 minutes at an impeller speed of $375 \mathrm{rpm}$ (ending with 5 seconds at $400 \mathrm{rpm}$ ). The dissociation reagent was then quenched 
with $70 \mathrm{ml}$ of culture medium and a $2 \mathrm{~mL}$ sample placed in a single well of a 6 well plate for analysis under a light microscope to assess cell detachment. The remainder of the solution was filtered through a $60 \mu \mathrm{m}$ Steriflip Filter Unit (Merck Millipore, Germany) to separate the microcarriers from the BMhMSCs. The cell suspension was centrifuged, the supernatant aspirated and the cell pellet resuspended in culture medium. A cell count was then performed using a NucleoCounter NC-3000 to assess the overall hMSC growth and the culture harvest efficiency.

\subsection{Spinner flask culture and harvest}

Full details of this aspect have been published previously [7]. In essence, the culture was undertaken in $100 \mathrm{~mL}$ spinner flasks (BellCo, USA) in an incubator in the presence of ambient air with the same type and concentration of microcarriers, with the cell concentration used in the bioreactor. All other conditions were also as in the bioreactor except that the agitation speed, $N_{\mathrm{ss}}$, was $30 \mathrm{rpm}$. Daily medium samples of $1 \mathrm{~mL}$ taken for analysis. BM-hMSCs were harvested using the same previously developed method $[19,20]$ as in the bioreactor, except that the agitation speed was $150 \mathrm{rpm}$ for $7-10$ min and $250 \mathrm{rpm}$ for the final few seconds. More details are given elsewhere [7].

\subsection{Analytical Techniques}

Analysis of glucose and lactate concentrations in the spent medium was performed using a Cedex BioHT (Roche, Germany). Cell counting, mean cell diameter and viability (via acridine orange uptake and DAPI exclusion) was performed using a NucleoCounter NC-3000 automated mammalian cell counter (Chemometec, Denmark). The following parameters were obtained:

1. Specific Growth Rate

$$
\text { Specific growth rate, } \mu=\frac{\ln \left({ }^{C_{x}(t)} / C_{x}(0)\right.}{\Delta t}
$$

where $\mu$ is the net specific growth rate $\left(h^{-1}\right), C_{x}(t)$ and $C_{x}(0)$ are the cell numbers at the end and start of the exponential growth phase, respectively and $t$ is time $(h)$. 
2. Population Doublings

$$
\text { Population Doublings, } P_{d}=\frac{1}{\log (2)} \cdot \log \left(\frac{C_{x}(t)}{C_{x}(0)}\right)
$$

where $P_{d}$ is the number of population doublings, $C_{x}(t)$ and $C_{x}(0)$ are the cell numbers at the end and start of the exponential growth phase, respectively.

3. Specific Metabolite Consumption/Production Rate

$$
\text { Specific metabolite flux, } q_{m e t}=\left(\frac{\mu}{C_{x}(0)}\right) \cdot\left(\frac{C_{m e t}(t)-C_{m e t}(0)}{e^{\mu t}-1}\right)
$$

where $q_{m e t}$ is the net specific metabolite consumption or production rate, $\mu$ is the specific growth rate $\left(h^{-1}\right), C_{x}(0)$ is the cell number at the end of the exponential growth phase, $C_{\text {met }}(t)$ and $C_{\text {met }}(0)$ are the metabolite concentrations at the end and start of the exponential growth phase, respectively and $t$ is time (h).

\subsection{Colony-forming unit fibroblast (CFU-f) Efficiency}

To assess the CFU-f efficiency, BM-hMSCs were seeded in a T-flask at 10 cells.cm ${ }^{-2}$ and cultured with a medium exchange every 3-5 days. Following 14 days culture, cells were washed with PBS and fixed in $4 \%$ formaldehyde (v/v) (Sigma, UK) for 30 minutes. Colonies were stained with $1 \%$ crystal violet (Sigma, UK) in $100 \%$ methanol (w/v) for 30 minutes. Stained colonies that were made up of more than 25 cells were recorded as CFUs.

\section{7 hMSC Characterization}

Immunophenotype analysis was performed by multiparameter flow cytometry before and after the hMSC expansion process using a previously developed protocol [21]. Morphology images were obtained using a light microscope (Nikon Eclipse TS-100, UK). 
The hMSC differentiation was induced using PRIME-XV Differentiation SFM (Irvine Scientific, USA) as per manufacturer's instructions. After 21 days the differentiation medium was removed, cells rinsed with PBS then fixed with 4\% (v/v) PFA at room temperature. Adipocytes were stained with $1 \%(\mathrm{w} / \mathrm{v})$ Oil Red O (Sigma-Aldrich, UK) in isopropanol at room temperature and rinsed with distilled water. Osteoblasts were incubated with $2.5 \%(\mathrm{v} / \mathrm{v}$ ) silver nitrate (Sigma-Aldrich, UK) under ultraviolet light (30 minutes exposure), rinsed with distilled water and stained with fast violet solution (Sigma-Aldrich, UK) containing 4\% (v/v) napthol AS-MX phosphate alkaline (Sigma-Aldrich, UK) for 45 minutes at room temperature in the dark. Chondrocytes were stained with $1 \%(\mathrm{w} / \mathrm{v})$ Alcian blue (Sigma-Aldrich, UK) in $0.1 \mathrm{M}$ hydrochloric acid (Sigma-Aldrich, UK). After 30 minutes incubation, cells were rinsed three times with $0.1 \mathrm{M} \mathrm{HCl}$. After staining, differentiated cells were visualized under a light microscope (Nikon Eclipse TS-100, UK).

\subsection{Statistical Analysis}

Results were deemed to be significant if $p<0.05$ using an unpaired two-tailed Students t-test.

\section{Results \& Discussion}

\subsection{Effect of dissolved oxygen concentration on BM-hMSC expansion on microcarriers}

Dissolved oxygen concentration has been previously shown to have an impact on BM-hMSC growth and cell characteristics [22], with much debate around the use of the terms "normoxia" $\left(100 \% \mathrm{dO}_{2}\right)$ and "hypoxia" (typically < $25 \% \mathrm{dO}_{2}$ ) [16]. Almost all of the current technology for BM-hMSC expansion utilize open, laboratory scale processes such as T-flasks (or occasionally spinner flasks) wherein controlling, monitoring, and evaluating the impact of key parameters on target cell output and productivity is difficult [23]. Control of process parameters such as dissolved oxygen during the manufacturing process will be vital in maximizing product consistency and ensuring that the process is scalable. A large part of this ability to control the process conditions is in maintaining a closed process 
during expansion, which not only reduces contamination risk but is vital in maintaining the desired culture environment of the BM-hMSCs and avoid fluctuations in these critical process parameters. Much of the current literature on low oxygen culture of BM-hMSC use hypoxic incubators that maintain a low oxygen environment (an oxygen concentration in the gas phase lower than that found in atmospheric air) rather than controlling the $\mathrm{dO}_{2}$ conditions in the actual bioreactor medium in T-flasks (or spinner flasks), with process manipulations taking place within the atmospheric oxygen concentrations.

Figure 1 shows the impact of exposing low dissolved oxygen $\left(\mathrm{dO}_{2}\right)$ experiments to atmospheric oxygen within an agitated bioreactor process simulating the exposure to such conditions during culture

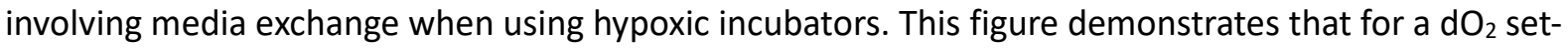
point of $5 \%$ (1.05\% atmospheric oxygen), after a one-hour exposure of the culture to atmospheric conditions ( $21 \%$ atmospheric oxygen equivalent to $100 \%$ dissolved oxygen at saturation), creates a deviation to a maximum $\mathrm{dO}_{2}$ concentration of $77.9 \%$, which takes a further 294 minutes to return to $5 \% \mathrm{dO}_{2}$ with continual headspace aeration with $1.05 \%$ atmospheric oxygen. Considering the number of manipulations that occur during culture, for example, daily sampling and medium exchange, this mode of operation causes large and prolonged fluctuations in dissolved oxygen concentrations experienced by the BM-hMSCs. This experiment has taken place in agitated conditions with headspace aeration, which represents a best-case scenario, as in static monolayer culture without headspace gassing these deviations in $\mathrm{dO}_{2}$ would be larger with an increased set-point recovery time. It is suggested that this variation in $\mathrm{dO}_{2}$ during processing is a potential reason why there is so much discrepancy within the published literature of BM-hMSCs cultured in low oxygen concentration atmospheres, with some groups suggesting that the optimal BM-hMSC culture condition occurs when the cells are never exposed to atmospheric oxygen levels, even during the initial isolation and banking phase [24]. In addition, of course, when "normoxic" (21\% atmospheric oxygen) is used, such variations do not occur. 
Figure $2 \mathrm{~A}$ shows the effect of various controlled dissolved oxygen concentrations on BM-hMSC 1 growth on microcarriers over six days of culture in FBS-containing medium, with increased growth kinetics at lower dissolved oxygen concentrations where each $\mathrm{dO}_{2}$ value was held constant throughout that time by performing culture sampling and medium exchange without exposing the culture to atmospheric conditions. This effect of $\mathrm{dO}_{2}$ is confirmed by Figure $2 \mathrm{~B}$, which shows the post-harvest cell number at each $\mathrm{dO}_{2}$ concentration, with significantly higher BM-hMSC numbers $(p<0.05)$ at 10 and $25 \% \mathrm{dO}_{2}$ compared with $100 \% \mathrm{dO}_{2}$. There is currently no common consensus in the literature on whether low oxygen concentrations are beneficial for BM-hMSCs, with some studies demonstrating improved growth [25] and function [26], whilst others, including our previously published work, demonstrates diminished BM-hMSC characteristics [16] in uncontrolled monolayer culture. These results suggest that for these donor cells (BM-hMSC 1), BM-hMSC growth characteristics are improved at low dissolved oxygen concentrations, when undertaken in a fully $\mathrm{dO}_{2}$ controlled microcarrier expansion process. More work of this type with fully controlled $\mathrm{dO}_{2}$ is required to establish whether low values are generally beneficial for BM-hMSC culture.

It is again important to assess the effect of changing $\mathrm{dO}_{2}$ concentrations on the relative metabolite flux of the BM-hMSC during microcarrier expansion. Supplementary figure 1 shows the concentrations of glucose, lactate and ammonia over the six days of expansion, with increased consumption of glucose and production of lactate in low dissolved oxygen concentrations, in accordance with the increased BM-hMSC growth rate. The production of ammonia in 10 and $25 \% \mathrm{dO}_{2}$ was reduced compared with higher $\mathrm{dO}_{2}$ concentrations, despite the increased $\mathrm{BM}-\mathrm{hMSC}$ number at the lower dissolved oxygen concentration. The LDH and total protein concentrations have been measured to assess whether any BM-hMSC stress or damage has been caused by the different $\mathrm{dO}_{2}$ concentrations, which did not change significantly through culture in any of the conditions (supplementary figure 2). The per cell flux of ammonia and the yield of lactate from glucose can be seen in figure $2 \mathrm{~A}$ and $2 \mathrm{~B}$ respectively for $\mathrm{BM}$ hMSC 1 culture on microcarriers at various controlled $\mathrm{dO}_{2}$ concentrations. The per cell flux of ammonia in figure $2 \mathrm{~A}$ shows a significant reduction $(\mathrm{p}<0.05)$ for both 25 and $10 \% \mathrm{dO}_{2}$ to around $2.5 \mathrm{pmol}^{\text {.cell }}{ }^{-}$ 
${ }^{1}$.day ${ }^{-1}$, compared to $100 \% \mathrm{dO}_{2}$. These findings are again in agreement with a previous study [25] and suggests a more efficient cell metabolism under low $\mathrm{dO}_{2}$ culture conditions. A reduction in the production in ammonia at low $\mathrm{dO}_{2}$ concentrations for microcarrier culture is also advantageous for process operation, as the build-up of toxic compounds to inhibitory levels will become less of an issue [27]. The yield of lactate production from glucose can be seen in figure $2 B$, which shows a reduction in yield to $1.21 \pm 0.37 \mathrm{~mol} . \mathrm{mol}^{-1}$ at $25 \% \mathrm{dO}_{2}$, but a subsequent increase at $10 \% \mathrm{dO}_{2}$ to $2.27 \pm 0.26$ mol.mol ${ }^{-1}$ compared with $100 \% \mathrm{dO}_{2}$. This result is in agreement with studies of BM-hMSC culture at low oxygen concentrations in monolayer involving BM-hMSCs $[16,25]$ but is significantly higher than BM-hMSCs derived from the umbilical cord at both high and low $\mathrm{dO}_{2}$ concentrations [28]. Considering the importance of the in vivo niche environment on hMSC characteristics, it is possible that this difference in cell metabolism at different dissolved oxygen concentrations is due to relative differences in the in vivo oxygen concentrations in the bone-marrow and umbilical cord tissues [29]. This difference may also help explain the varying results in the literature.

It is also important to assess whether microcarrier expansion at reduced $\mathrm{dO}_{2}$ concentrations is not unduly affecting the post-harvest BM-hMSC characteristics, despite the improved growth kinetics seen previously. Figure 3A shows the outgrowth rate of BM-hMSC 1 after harvesting from the microcarriers at the various $\mathrm{dO}_{2}$ concentrations compared to pre-expansion (prior to expansion in the bioreactor) and post-harvest from the spinner flasks in a controlled environment cabinet with atmospheric air ( $\left.100 \% \mathrm{dO}_{2}\right)$. This comparison shows significantly higher $(\mathrm{p}<0.05)$ outgrowth kinetics for BM-hMSCs across all controlled bioreactor expansion conditions including $100 \% \mathrm{dO}_{2}$ compared to pre-expansion and post-harvest from the spinner flasks. In addition to this, BM-hMSCs cultured at $10 \% \mathrm{dO}_{2}$ demonstrated significantly higher $(p<0.05)$ outgrowth kinetics compared to all other controlled $\mathrm{dO}_{2}$ concentrations. These results suggest that the controlled $\left(\mathrm{pH}\right.$ and $\left.\mathrm{dO}_{2}\right)$ expansion of $\mathrm{BM}-\mathrm{hMSCs}$ on microcarriers in bioreactors at $100 \% \mathrm{dO}_{2}$ is having a positive impact on the outgrowth kinetics of $\mathrm{BM}$ - 
hMSCs compared to the less-well controlled conditions in spinner flasks. In addition, for these cells, low dissolved oxygen concentrations further enhances that improvement.

In accordance with the increase in outgrowth kinetics, the mean cell diameter of BM-hMSCs cultured in the controlled bioreactor conditions in figure 3B is significantly $(p<0.05)$ lower than pre-expansion and post-harvest from spinner flasks. The benefits to the manufacturing process of producing smaller BM-hMSCs has previously been discussed [30] and smaller cells are commonly associated with increased proliferation, greater colony-forming efficiency and longer telomeres [31]. Likewise, BMhMSC culture at low $\mathrm{dO}_{2}$ from different sources may also display different functional characteristics and can modulate the autocrine or paracrine activity of a variety of cytokines and growth factors in BM-hMSCs [32]. The post-harvest colony-forming (CFU) efficiency of BM-hMSCs from the controlled bioreactor process at various $\mathrm{dO}_{2}$ concentrations can be seen in figure $3 \mathrm{C}$, which shows a similar level of CFU efficiency for BM-hMSC harvested form 50 and $100 \% \mathrm{dO}_{2}$ conditions, compared with pre- and

post- expansion spinner flask culture. In contrast, the post-harvest CFU efficiency of BM-hMSC from 10 and $25 \% \mathrm{dO}_{2}$ was significantly higher $(\mathrm{p}<0.05)$ than pre-expansion and post-harvest from spinner flasks. An increase in CFU efficiency of BM-hMSCs at low dissolved oxygen has previously been reported and has been shown to be independent of hypoxia inducible factor (HIF) expression in BMhMSCs [33].

\subsection{Controlled microcarrier expansion of BM-hMSC donors in serum-free}

Following the development of a process control strategy in FBS-based culture, it is important to assess the effect of this new control strategy on the serum-free (SFM) microcarrier expansion of multiple BMhMSC donors. $\mathrm{A} \mathrm{DO}_{2}$ concentration of $25 \%$ was selected for the controlled expansion in SFM, due to the previous data that showed increased culture performance at low $\mathrm{DO}_{2}$ concentrations. Specifically, at $\mathrm{DO}_{2}$ concentration of $25 \%$ was selected over $10 \% \mathrm{DO}_{2}$ due to the increased lactate production experienced at $10 \% \mathrm{DO}_{2}$, which could be detrimental to the culture, particularly as the BM-hMSC density increases. Figure 4A shows the growth rate of the two donor BM-hMSC lines, BM-hMSC 1 and 
2, in controlled bioreactors in FBS and SFM, with a significantly increased growth rate for both BMhMSC donors in SFM to a final cell concentration of $7.11 \pm 0.90 \times 10^{5}$ cell. $\mathrm{mL}^{-1}$ for BM-hMSC 1 and 6.13 $\pm 1.82 \times 10^{5}$ cell. $\mathrm{mL}^{-1}$ for BM-hMSC 2 . This improvement represents a $300 \%$ increase in the BM-hMSC yield across the two donors in SFM compared to that in FBS, which will be advantageous in driving cost-effective BM-hMSC manufacturing processes. The increase in growth kinetics in a controlled SFM microcarrier process presented here is in accordance with our previously published data for monolayer culture [30] and uncontrolled spinner flask culture [8].

The harvest efficiency of BM-hMSC from the FBS-based process was $91.5 \pm 8.9 \%$ across both donors, which is comparable to previous studies which demonstrated $>95 \%$ harvest efficiency for a spinner flask based harvesting process [20]. This result also demonstrates the effectiveness of the scalable harvesting method developed on sound engineering principals, as despite the change in bioreactor platform, maintaining the same detachment protocol for the DASbox bioreactor platform has yielded a similar BM-hMSC harvest efficiency [19] to that in spinner flasks. The overall harvest efficiency of the BM-hMSCs from the SFM process, however, was $76.5 \pm 2.9 \%$, significantly lower than the previous FBS-based microcarrier processes. This drop is most likely due to the significantly increased BM-hMSC densities achieved under serum-free conditions, reducing the effectiveness of the separation process. Supplementary figure 3 shows that the harvest procedure employed has successfully removed the BMhMSCs from the microcarriers in the SFM process. Therefore, the reduction in harvest efficiency can be attributed to losses during the subsequent cell-microcarrier separation by filtration followed by cell concentration. This separation problem will clearly have to be addressed moving forward, as increased cell densities will be required in order to drive cost-effective manufacturing processes and harvesting efficiencies will have fundamental impact on final product yields [34]. Part of this success will be in developing scalable downstream technology, capable of reducing losses in the process step of separating the BM-hMSCs from the microcarriers after detachment [35]. 
Metabolite analysis of the controlled bioreactor microcarrier culture of BM-hMSCs showed differences in the metabolic pathway usage relating to lactate and ammonia production between FBS-containing and serum-free cultures. Figure 4 shows the relative consumption of glucose (B), production of lactate (C) and ammonia (D), as well as the yield of lactate from glucose (E) in FBS and SFM for two donor BMhMSC lines. In FBS-based expansion the consumption of glucose was $9.86 \pm 1.49$ pmol.cell $^{-1}$.day ${ }^{-1}$ for BM-hMSC 1 and $8.37 \pm 1.94$ pmol.cell ${ }^{-1}$.day ${ }^{-1}$ for BM-hMSC 2, whereas for SFM expansion the consumption of glucose was significantly lower $(p<0.05)$ for both BM-hMSC donors with $4.41 \pm 0.14$ pmol.cell ${ }^{-1}$.day ${ }^{-1}$ for BM-hMSC 1 and $3.54 \pm 1.40$ pmol.cell $^{-1}$.day ${ }^{-1}$ for BM-hMSC 2. Similarly, the production of lactate in the controlled microcarrier process was significantly lower $(p<0.05)$ in the SFM process compared to the FBS-based process for both donor BM-hMSC lines. This result is once again comparable to the levels of glucose and lactate flux measured during monolayer [30] and uncontrolled microcarrier culture [8] using the same donor BM-hMSCs. As with these previous studies, the production of ammonia is more similar between the FBS and SFM conditions indicating that the metabolite utilization under SFM conditions is more efficient, with a switch from energy production predominantly via anaerobic glycolysis in FBS culture to utilization of the oxidative phosphorylation pathway under SFM. The metabolite utilization between BM-hMSC donors is also more consistent in controlled SFM microcarrier culture, with a range in the yield of lactate from glucose between BMhMSC 1 and 2 of $0.12 \mathrm{~mol}^{\mathrm{mol}}{ }^{-1}$. In contrast, the yield of lactate from glucose in controlled FBS culture between donors showed a range of $1.32 \mathrm{~mol}^{\mathrm{mol}} \mathrm{m}^{-1}$. This increase in consistency of BM-hMSC characteristics between donors in controlled SFM culture offers significant advantages for bioprocess development and has been maintained from monolayer culture of BM-hMSCs, demonstrating comparable process transfer throughout development. 
The concentrations of LDH and total protein for controlled bioreactor culture on microcarriers in FBS and SFM for two BM-hMSC donors can be seen in figure 5. The FBS-based process demonstrated little increase in LDH or total protein over the six days of culture, suggesting no significant cell damage is occurring during the expansion process. The total protein concentration in controlled SFM expansion also showed no significant increase over the six days of culture. However, the LDH concentration did see a slight increase on day six, when the cell density is at a maximum, up to the baseline level during FBS culture. Considering that this occurs at increased BM-hMSC densities, this outcome should be evaluated as the final cell density of BM-hMSC bioreactor processes increase, to ensure that increasing the yield does not impact the quality of the product.

It is evident from figure $6 \mathrm{~A}$ that the attachment efficiency of BM-hMSCs in the bioreactor to the microcarriers is improved for both donors in the SFM expansion process, with $>75 \%$ attachment efficiency after one day. In contrast, the FBS-based process had an attachment efficiency of $<70 \%$ for both donors after one day, with a reduced attachment in the subsequent four days of expansion. This is likely due to the use of fibronectin to coat the microcarriers in the SFM process, which has been shown to improve cell attachment [36]. Given the implications of poor cell-microcarrier attachment described above, particularly as the process increases in scale, this higher level of attachment represents a key advantage of the SFM compared to the FBS-based microcarrier process.

The specific outgrowth rate of BM-hMSCs from both the FBS and SFM controlled bioreactor processes can be seen in figure $6 \mathrm{~B}$ which shows that the post-harvest outgrowth kinetics of BM-hMSC have been maintained. Figure 6C shows the post-harvest BM-hMSC diameter which has been significantly reduced $(p<0.05)$ compared to pre-expansion, which for the FBS process represented a reduction of 2.1 $\mu \mathrm{m}$ for BM-hMSC 1 and $2.2 \mu \mathrm{m}$ for BM-hMSC 2 . This is in contrast to the uncontrolled spinner flask process presented previously [8] which demonstrated a slight increase in mean cell diameter of BMhMSC $1 .(1.2 \mu \mathrm{M})$ and BM-hMSC $2(0.4 \mu \mathrm{m})$ between post-harvest and pre-expansion. The post-harvest 
colony-forming potential of the BM-hMSCs can be seen in figure $6 \mathrm{D}$, which shows that the CFU potential has either increased or been maintained compared to pre-expansion. This is particularly apparent for the controlled FBS-based process, which showed a significant increase $(p<0.05)$ in the post-harvest CFU potential for both BM-hMSC donor lines. Verification of post-harvest immunophenotype and differential potential of BM-hMSCs used during this study can be seen in Supplementary Figure 4.

\subsection{Process control to drive yield and consistency into BM-hMSC manufacture}

For these BM-hMSC therapies to successfully progress through to commercial production, the manufacturing cost of goods should be minimized, and the process robustness maximized throughout development. Driving yield and consistency into the BM-hMSC manufacturing process at an early stage of development will be critical to reduce the overall cost of goods and increase the cost-effectiveness of the final BM-hMSC product. Increasing the consistency of the final product will reduce process costs by demonstrating a level of control over the product and reducing the risk of batch failure. For largescale off the shelf processes, where the capital invested per batch is high, increasing the consistency of product quality will reduce the risk of product batch failures and significantly reduce the overall production costs. This means that assessing the final BM-hMSC yield and donor consistency for various process iterations, would be highly informative on the direction of future manufacturing development. Currently, two of the key cost drivers for the production of off-the-shelf cell-based therapies are in the culture medium and the time it takes to manufacture a product batch in a facility [6]. Therefore, to make a basic yield comparison of each of the processes developed, the relative process yield in terms of number of BM-hMSCs produced as a function of the volume of culture medium and process time has been calculated for each of the controlled and uncontrolled systems.

In addition to this process yield estimation, a combination of the inter- and intra-donor variation has been assessed to get an understanding of the relative consistency within each process. The results of this can be seen in figure 7 , which demonstrates the increased process yield that is achieved in 
controlled SFM microcarrier culture. This improvement represents an increase in process yield of over $300 \%$ for the SFM process compared to the FBS based process under the controlled conditions of the bioreactor. As the process scale increases and the manufacturing costs of the SFM are reduced, this improvement is likely to increase further, due to the issues associated with serum supply at a largescale [37]. It can also be seen from figure 7 that the process yield is also increased by an average of around $500 \%$ for both donors under controlled conditions compared to the poorly controlled expansion in spinner flasks, highlighting the importance of systematically developing a process control strategy to increase the yield of BM-hMSC production on microcarriers. It is important to note that the large difference in process yield between monolayer and microcarrier culture at the bench-scale evaluated here, will increase as the scale increases, due to the improved economies of scale achievable in a suspension bioreactor-based process.

The percentage coefficient of variation has been calculated for each of the expansion processes to assess the relative amount of variation in cell yield between each condition. This parameter is a combination of inter-donor variation, (the variation between each donor) and intra-donor variation (the variation between batch runs of each donor), as seen in figure 7 , which shows the lowest coefficient of variation for the controlled SFM microcarrier process with $14.7 \%$. A coefficient of variation of $15 \%$ or less is in alignment with the established regulatory guidance [38, 39], demonstrating control over the product. There is also a clear difference between the controlled and uncontrolled processes in FBS, with process control reducing the coefficient of variation from $79.1 \%$ for the spinner flask to $37.5 \%$ for the bioreactor experiments. In addition to the scalability of stirredtank bioreactors versus alternative BM-hMSC culture technology, this further demonstrates that stirred-tank bioreactors can achieve effective process control across a number of process parameters, utilizing online and non-destructive methods to maintain the process in a state of control for the duration of the culture. This outcome represents a significant reduction in process variation, via the introduction of a process control system, once again demonstrating the importance of developing a process control strategy for BM-hMSC production. 


\section{Conclusions}

The systematic development of a process control strategy in a stirred-tank bioreactor for the microcarrier expansion of BM-hMSCs has significantly increased the yield and consistency achievable in the process compared to the relatively-uncontrolled conditions in a spinner flask. Even operating the microcarrier expansion process for BM-hMSCs in closed system with controlled $\mathrm{pH}$ and at $100 \%$ $\mathrm{dO}_{2}$, has demonstrated improved growth and post-harvest BM-hMSC quality characteristics compared to those produced from a spinner flask in atmospheric air in biological safety cabinets.

Studies looking at the effect of exposing cells grown at low dissolved oxygen ("hypoxic") conditions during bioreactor culture to atmospheric conditions during the culture period, as can occur during media exchange, etc., has highlighted the importance of operating closed and controlled processes to avoid large fluctuation of the dissolved oxygen concentration of the medium. Thus, for closed conditions for these donor cells grown at 10 and $25 \% \mathrm{dO}_{2}$ in FBS-based medium, a further improvement was achieved compared to $100 \% \mathrm{dO}_{2}$.

The introduction of serum-free medium into such controlled low $\mathrm{dO}_{2}$ conditions has further increased the yield across two BM-hMSC donors, however, with reduced harvest efficiency compared to the FBSbased process that has lower cell numbers at harvest. It is argued that this drop was primarily due to cell losses in the cell-microcarrier separation step (filtration). Thus, it will be imperative to develop specific downstream technology to effectively separate the cells from the microcarriers, especially as the number of BM-hMSCs per volume is increased under serum-free conditions.

The development of a process control strategy has significantly increased the yield and consistency between BM-hMSC donors with a coefficient of variance between and within these donors under serum-free conditions of less than $15 \%$. This increase in consistency is in conjunction with a significant increase in the BM-hMSCs produced per volume of medium per unit time under serum-free 
conditions, which will be critical in increasing the economies of scale and reducing the cost of BMhMSC therapies. Furthermore, the introduction of the process control strategy has significantly reduced the BM-hMSC inter- and intra-donor variation in FBS-based culture from 79.1 to $37.5 \%$, which will be critical for the future development of both patient-specific and off-the-shelf BM-hMSC manufacturing processes.

\section{Acknowledgments}

This study has been funded by the Engineering and Physical Sciences Research Council (EPSRC, EP/F500491/1) and FUJIFILM Diosynth Biotechnologies. 


\section{References}

[1] Caplan Al, Dennis JE. Mesenchymal stem cells as trophic mediators. Journal of cellular biochemistry 2006;98:1076-84.

[2] Heathman TRJ, Nienow AW, McCall MJ, Coopman K, Kara B, Hewitt CJ. The translation of cellbased therapies: clinical landscape and manufacturing challenges. Regenerative medicine 2015;10:49-64.

[3] TiGenix and Takeda announce Alofise ${ }^{\circledR}$ (darvadstrocel) receives approval to treat complex perianal fistulas in Crohn's disease in Europe. Press Release 2018; https://www.takeda.com/newsroom/newsreleases/2018/tigenix-and-takeda-announcealofisel-receives-approval-in-europe/.

[4] Rafiq QA, Brosnan KM, Coopman K, Nienow AW, Hewitt CJ. Culture of human mesenchymal stem cells on microcarriers in a 5 I stirred-tank bioreactor. Biotechnology letters 2013;35:1233-45.

[5] Nienow AW. Reactor engineering in large scale animal cell culture. Cytotechnology 2006;50:9-33. [6] Simaria AS, Hassan S, Varadaraju H, Rowley J, Warren K, Vanek P, et al. Allogeneic cell therapy bioprocess economics and optimization: Single-use cell expansion technologies. Biotechnology and bioengineering 2014;111:69-83.

[7] dos Santos F, Andrade PZ, Abecasis MM, Gimble JM, Chase LG, Campbell AM, et al. Toward a Clinical-Grade Expansion of Mesenchymal Stem Cells from Human Sources: A Microcarrier-Based Culture System Under Xeno-Free Conditions. Tissue Engineering Part C, Methods 2011;17:1201-10. [8] Heathman TRJ, Glyn VAM, Picken A, Rafiq QA, Coopman K, Nienow AW, et al. Expansion, harvest and cryopreservation of human mesenchymal stem cells in a serum-free microcarrier process. Biotechnology and bioengineering 2015;112:1696-707.

[9] Tan KY, Teo KL, Lim JF, Chen AK, Reuveny S, Oh SK. Serum-free media formulations are cell linespecific and require optimization for microcarrier culture. Cytotherapy 2015;17:1152-65.

[10] Williams DJ, Thomas RJ, Hourd PC, Chandra A, Ratcliffe E, Liu Y, et al. Precision manufacturing for clinical-quality regenerative medicines. Philosophical transactions Series A, Mathematical, physical, and engineering sciences 2012;370:3924-49.

[11] Naing MW, Gibson DA, Hourd P, Gomez SG, Horton RBV, Segal J, et al. Improving umbilical cord blood processing to increase total nucleated cell count yield and reduce cord input wastage by managing the consequences of input variation. Cytotherapy 2015;17:58-67.

[12] FDA. Guidance for Industry Q8(R2) Pharmaceutical Development In: Services USDoHaH, editor. www.fda.gov/downloads/Drugs/Guidances/ucm073507.pdf2009.

[13] FDA. PAT - A framework for Innovative Pharmaceutical Development, Manufacturing and Quality Assurance. In: Center of Drug Evaluation and Research FaDA, editor.2004.

[14] Cierpka K, Elseberg CL, Niss K, Kassem M, Salzig D, Czermak P. hMSC Production in Disposable Bioreactors with Regards to GMP and PAT. Chemie Ingenieur Technik 2013;85:67-75.

[15] Nienow AW. Scale-Up, Stirred Tank Reactors. In: Encyclopedia of Industrial Biotechnology, (Ed, M C Flickinger), John Wiley \& Sons, Inc, Hoboken, NJ, USA 2010;7:4328-41.

[16] Rafiq QA, Coopman K, Nienow AW, Hewitt CJ. A quantitative approach for understanding smallscale human mesenchymal stem cell culture - implications for large-scale bioprocess development. Biotechnology journal 2013;8:459-71.

[17] Nienow AW, Coopman K, Heathman TR, Rafiq QA, Hewitt CJ. Bioreactor Engineering Fundamentals for Stem Cell Manufacturing. In "Stem Cell Manufacturing", (Eds. J.M.S. Cabral, C.L. de Silva, L. G. Chase and M. M. Diogo). Elsevier Science, Cambridge, USA 2017;Chapter 3:43-76. [18] Heathman TRJ, Nienow AW, Rafiq QA, Coopman K, Kara B, Hewitt CJ. Agitation and aeration of stirred-bioreactors for the microcarrier culture of human mesenchymal stem cells and potential implications for large scale bioprocess development. Biochemical Engineering Journal; In Press. [19] Nienow AW, Hewitt CJ, Heathman TRJ, Glyn VAM, Fonte GN, Hanga MP, et al. Agitation conditions for the culture and detachment of hMSCs from microcarriers in multiple bioreactor platforms. Biochemical Engineering Journal 2016;108:24-9. 
[20] Nienow AW, Rafiq QA, Coopman K, Hewitt CJ. A potentially scalable method for the harvesting of hMSCs from microcarriers. Biochemical Engineering Journal 2014;85:79-88.

[21] Chan AKC, Heathman TRJ, Coopman K, Hewitt CJ. Multiparameter flow cytometry for the characterisation of extracellular markers on human mesenchymal stem cells. Biotechnology letters 2014;36:731-41.

[22] Grayson WL, Zhao F, Izadpanah R, Bunnell B, Ma T. Effects of hypoxia on human mesenchymal stem cell expansion and plasticity in 3D constructs. Journal of cellular physiology 2006;207:331-9. [23] Kirouac DC, Zandstra PW. The systematic production of cells for cell therapies. Cell Stem Cell 2008;3:369-81.

[24] Kay AG, Dale TP, Akram KM, Mohan P, Hampson K, Maffulli N, et al. BMP2 repression and optimized culture conditions promote human bone marrow-derived mesenchymal stem cell isolation. Regenerative Medicine 2015;10:109-25.

[25] Dos Santos F, Andrade PZ, Boura JS, Abecasis MM, da Silva CL, Cabral JM. Ex vivo expansion of human mesenchymal stem cells: a more effective cell proliferation kinetics and metabolism under hypoxia. J Cell Physiol 2010;223:27-35.

[26] Basciano L, Nemos C, Foliguet B, de Isla N, de Carvalho M, Tran N, et al. Long term culture of mesenchymal stem cells in hypoxia promotes a genetic program maintaining their undifferentiated and multipotent status. BMC cell biology 2011;12:12.

[27] Schop D, Janssen FW, van Rijn LDS, Fernandes H, Bloem RM, de Bruijn JD, et al. Growth, Metabolism, and Growth Inhibitors of Mesenchymal Stem Cells. Tissue Engineering Part A 2009;15:1877-86.

[28] Lavrentieva A, Majore I, Kasper C, Hass R. Effects of hypoxic culture conditions on umbilical cordderived human mesenchymal stem cells. Cell Commun Signal 2010;8:18.

[29] Mohyeldin A, Garzón-Muvdi T, Quiñones-Hinojosa A. Oxygen in Stem Cell Biology: A Critical Component of the Stem Cell Niche. Cell stem cell 2010;7:150-61.

[30] Heathman TRJ, Stolzing A, Fabian C, Rafiq QA, Coopman K, Nienow AW, et al. Serum-free process development: improving the yield and consistency of human mesenchymal stromal cell production. Cytotherapy 2015;17:1524-35.

[31] Samsonraj RM, Rai B, Sathiyanathan P, Puan KJ, Rotzschke O, Hui JH, et al. Establishing criteria for human mesenchymal stem cell potency. Stem cells (Dayton, Ohio) 2015;33:1878-91.

[32] Das $\mathrm{R}$, Jahr $\mathrm{H}$, van Osch GJ, Farrell E. The role of hypoxia in bone marrow-derived mesenchymal stem cells: considerations for regenerative medicine approaches. Tissue engineering Part $B$, Reviews 2010;16:159-68.

[33] Tamama K, Kawasaki H, Kerpedjieva SS, Guan J, Ganju RK, Sen CK. Differential roles of hypoxia inducible factor subunits in multipotential stromal cells under hypoxic condition. Journal of cellular biochemistry 2011;112:804-17.

[34] Hassan S, Simaria AS, Varadaraju H, Gupta S, Warren K, Farid SS. Allogeneic cell therapy bioprocess economics and optimization: downstream processing decisions. Regenerative medicine 2015;10:591-609.

[35] Cunha B, Aguiar T, Silva MM, Silva RJ, Sousa MF, Pineda E, et al. Exploring continuous and integrated strategies for the up- and downstream processing of human mesenchymal stem cells. J Biotechnol 2015.

[36] Cooke MJ, Phillips SR, Shah DS, Athey D, Lakey JH, Przyborski SA. Enhanced cell attachment using a novel cell culture surface presenting functional domains from extracellular matrix proteins.

Cytotechnology 2008;56:71-9.

[37] Brindley DA, Davie NL, Culme-Seymour EJ, Mason C, Smith DW, Rowley JA. Peak serum: implications of serum supply for cell therapy manufacturing. Regenerative medicine 2012;7:7-13.

[38] Streitz M, Miloud T, Kapinsky M, Reed MR, Magari R, Geissler EK, et al. Standardization of whole blood immune phenotype monitoring for clinical trials: panels and methods from the ONE study. Transplantation Research 2013;2:17-. 
[39] FDA. Guidance for Industry. Potency tests for cellular and gene therapy products. In: Administration USFaD, editor.

http://www.fda.gov/downloads/BiologicsBloodVaccines/GuidanceComplianceRegulatorylnformation GGuidances/CellularandGeneTherapy/UCM243392.pdf2011. 


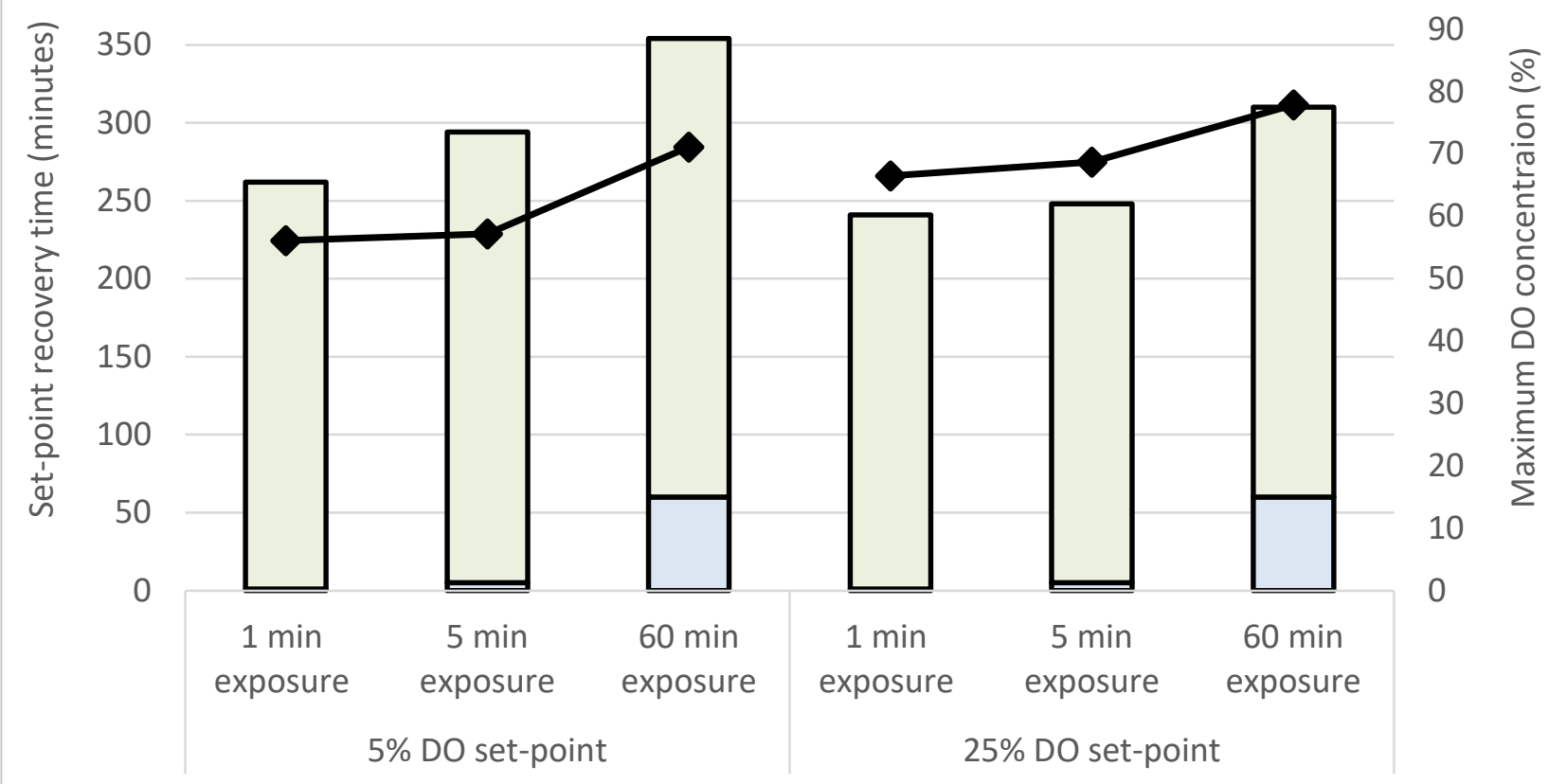

Figure 1 - Implications of exposing low dissolved oxygen $\left(\mathrm{dO}_{2}\right)$ cultures $\left(5 \% \mathrm{dO}_{2}\right.$ and $\left.25 \% \mathrm{dO}_{2}\right)$ in a biological safety cabinet to normal atmospheric conditions for 1,5 and 60 minutes. Demonstrating the importance of continuous closed process control during bioreactor culture. Bars represent the set-point recovery time to 5 or $25 \% \mathrm{dO}_{2}$ and diamonds represent the maximum $\mathrm{dO}_{2}$ concentration reached during each exposure and recovery period. 
A

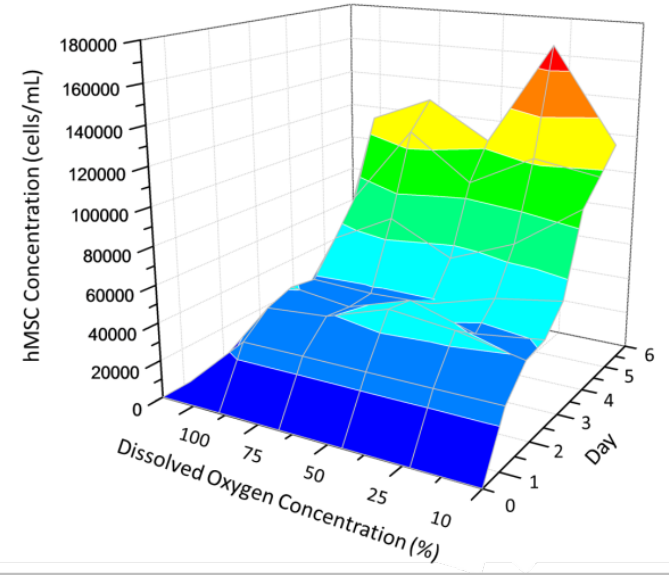

C

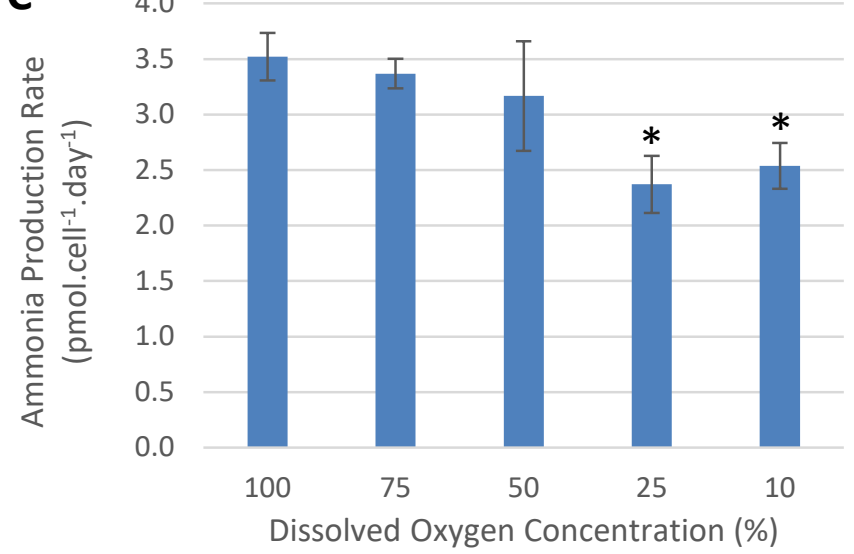

B $\quad 1.4 \mathrm{E}+07$

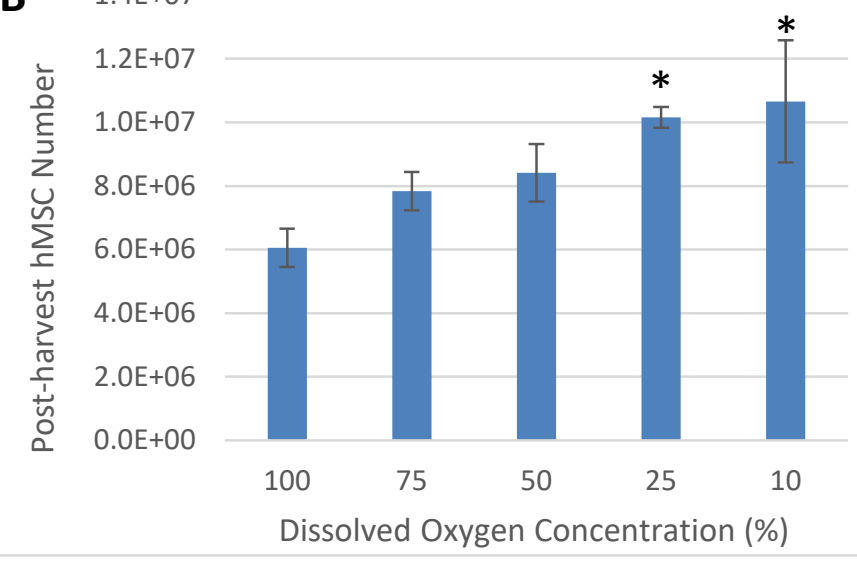

D $\quad 3.0$
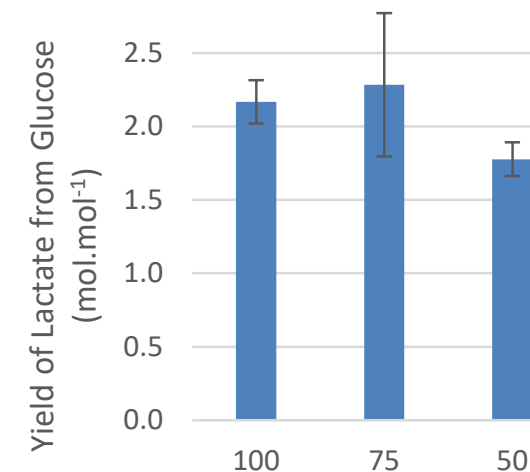

Dissolved Oxygen Concentration (\%)

Figure 2 - Effect of dissolved oxygen $\left(\mathrm{dO}_{2}\right)$ on $\mathrm{BM}$-hMSC 1 growth over six days of culture in FBS-containing medium in the DASbox controlled bioreactor, showing increased cell numbers over six days at lower dissolved oxygen concentrations (A) pre-harvest, (B) post-harvest, (C) per cell flux of ammonia and (D) yield of lactate from glucose. Control set-points are 115rpm impeller speed and $\mathrm{pH} 7.4$ with headspace aeration. Data shows mean $\pm S D, n=3$. ${ }^{*}$ denotes a significant difference $(p<0.05)$ compared to $100 \% \mathrm{DO}_{2}$. 

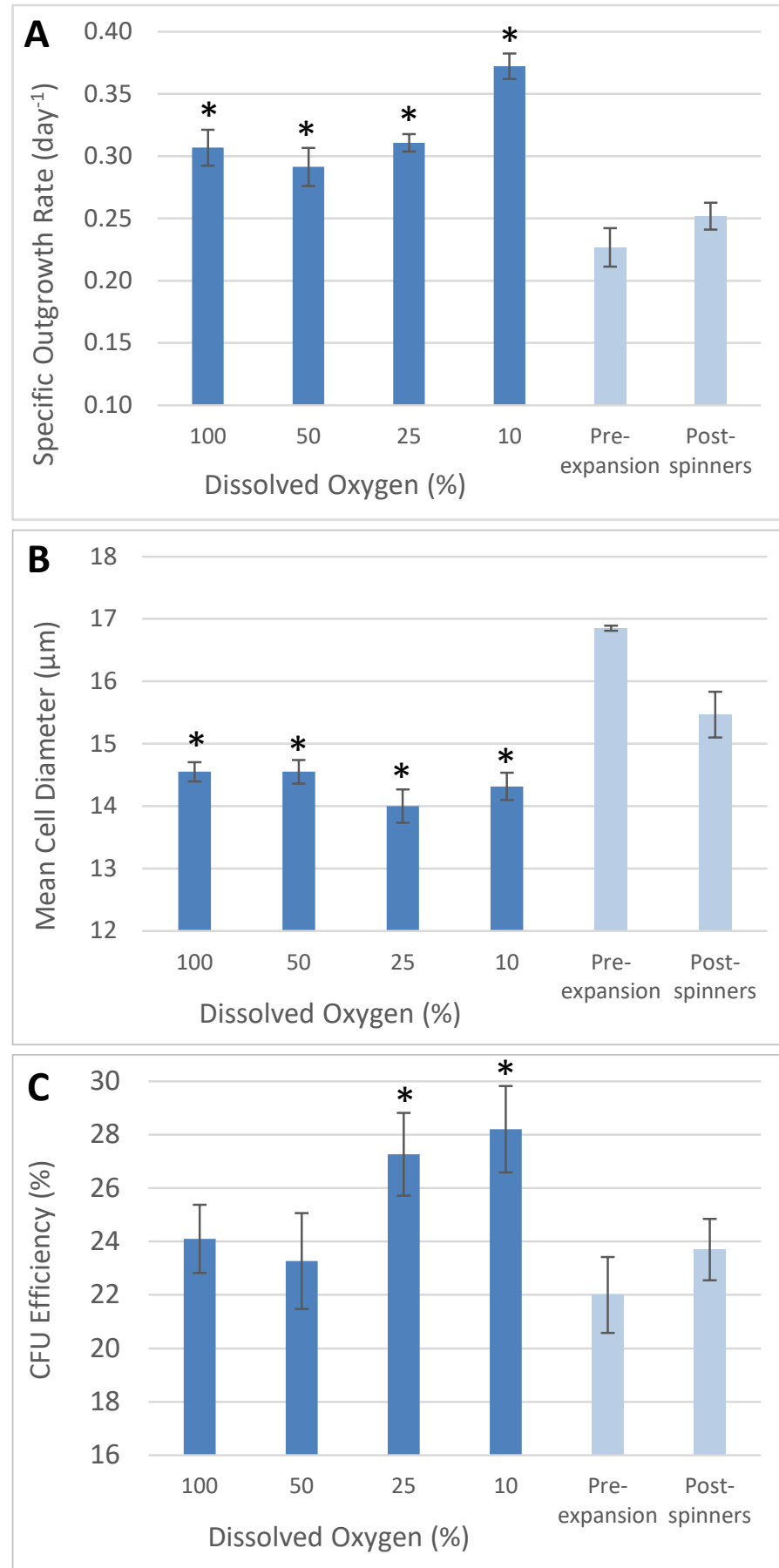

Figure 3 - Post-harvest characteristics of BM-hMSC 1 from controlled microcarrier culture in FBS-containing medium compared to pre-expansion and post-harvest from spinner flasks in a controlled environment cabinet with atmospheric air $\left(\sim 100 \% d_{2}\right)$. Showing $(A)$ increased outgrowth rate; (B) reduced mean cell diameter; and (C) increased CFU efficiency at reduced $\mathrm{dO}_{2}$ concentrations in the bioreactor and improved performance at all $\mathrm{dO}_{2}$ concentrations compared to the spinner flasks. Data shows mean $\pm S D, n=3$. $*$ denotes a significant difference $(p<0.05)$ compared to pre-expansion and post-spinners. 

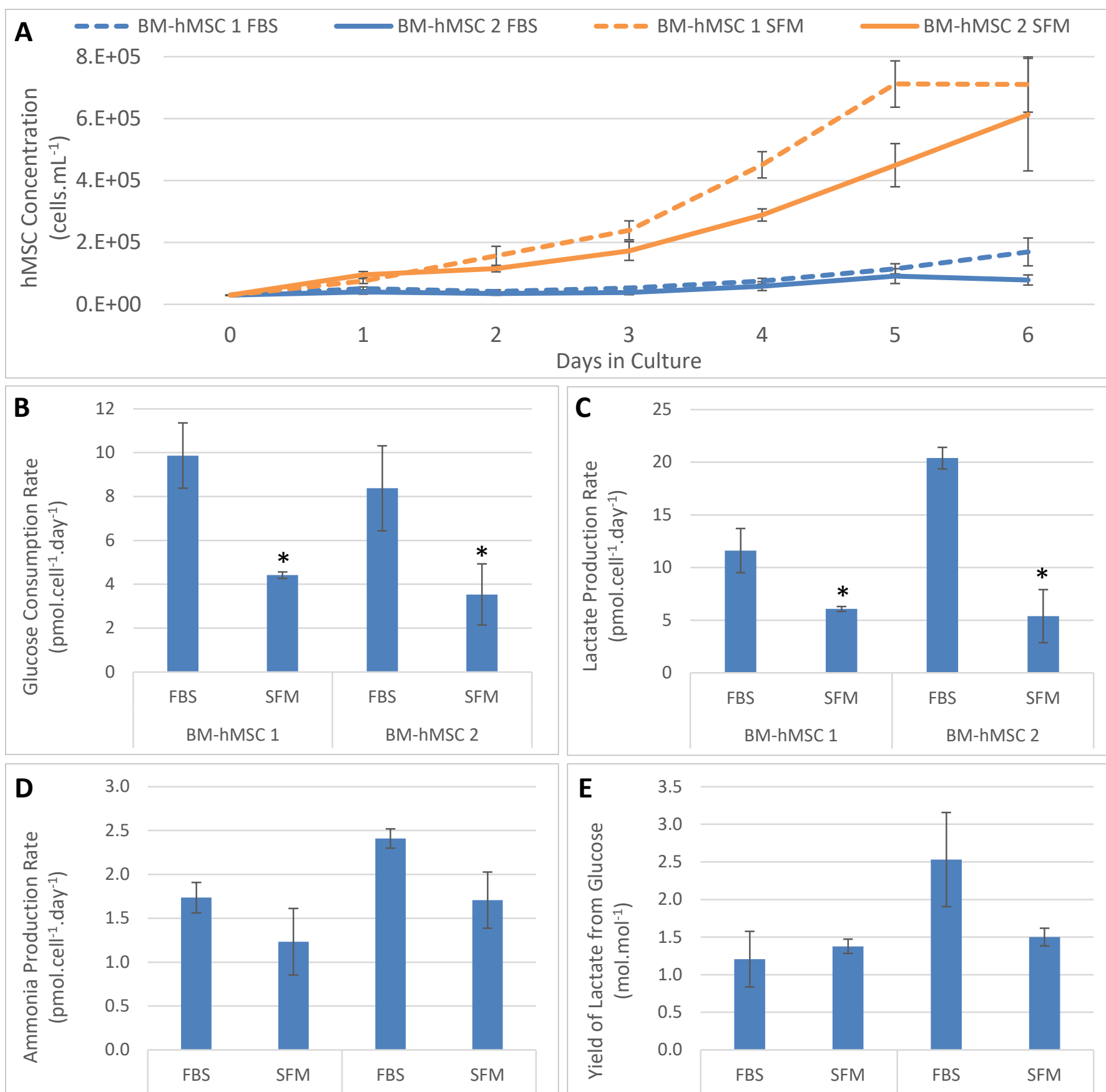

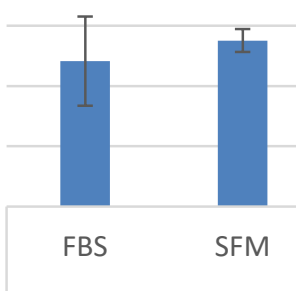

BM-hMSC 1
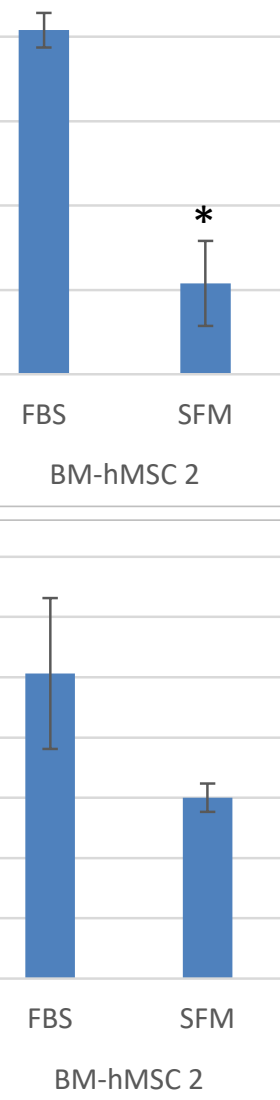

Figure 4 - Comparison of culture on microcarriers in the bioreactor in FBS and SFM across the two BM-hMSC donors at $115 \mathrm{rpm}$, with controlled $25 \%$ $\mathrm{dO}_{2}$ by headspace aeration and a $\mathrm{pH}$ of 7.4. Showing (A) increased growth rate for both donors in SFM, (B) reduced glucose consumption in SFM, (C) reduced lactate production in SFM, (D) reduced ammonia production in SFM and $(E)$ yield of lactate from glucose. Data shows mean $\pm S D, n=3$. ${ }^{*}$ denotes a significant difference $(p<0.05)$ compared with the same BM-hMSCs in FBScontaining medium. 


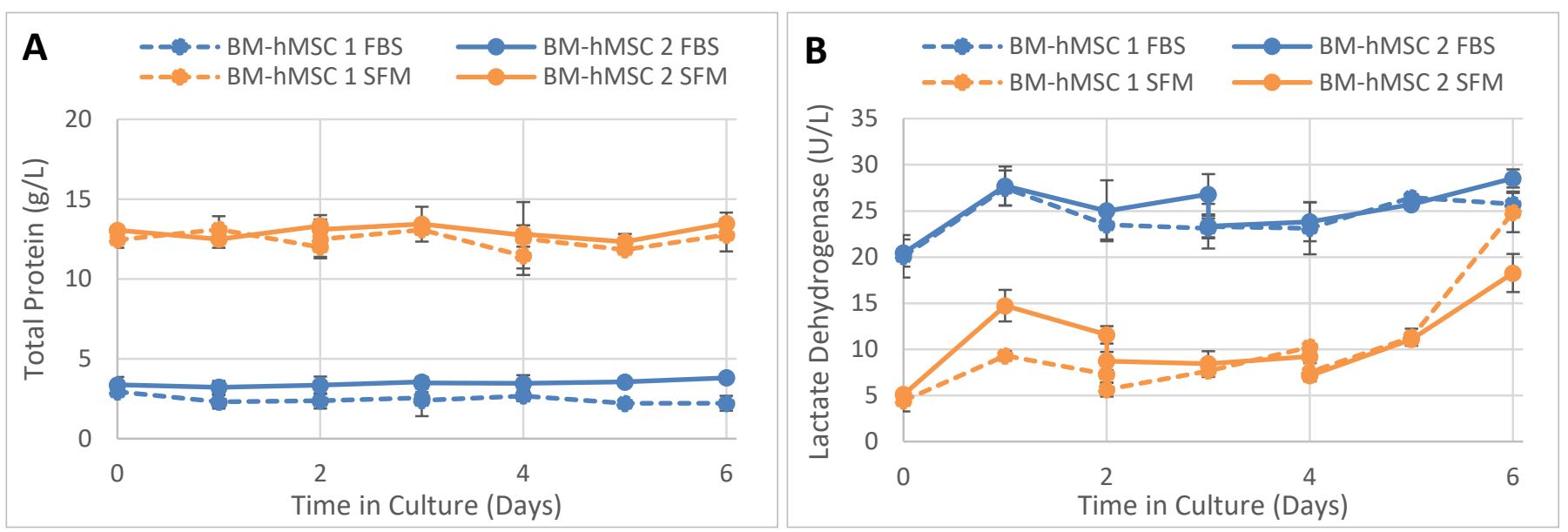

Figure 5 - Comparison of culture on microcarriers in the bioreactor in FBS and SFM across two BM-hMSC donors at $115 \mathrm{rpm}$, with controlled $25 \% \mathrm{dO}_{2}$ by headspace aeration and a $\mathrm{pH}$ of 7.4. Showing (A) no increase in total protein concentration over six days and (B) increased LDH concentration at the end of SFM culture. Data shows mean $\pm S D, n=3$. 

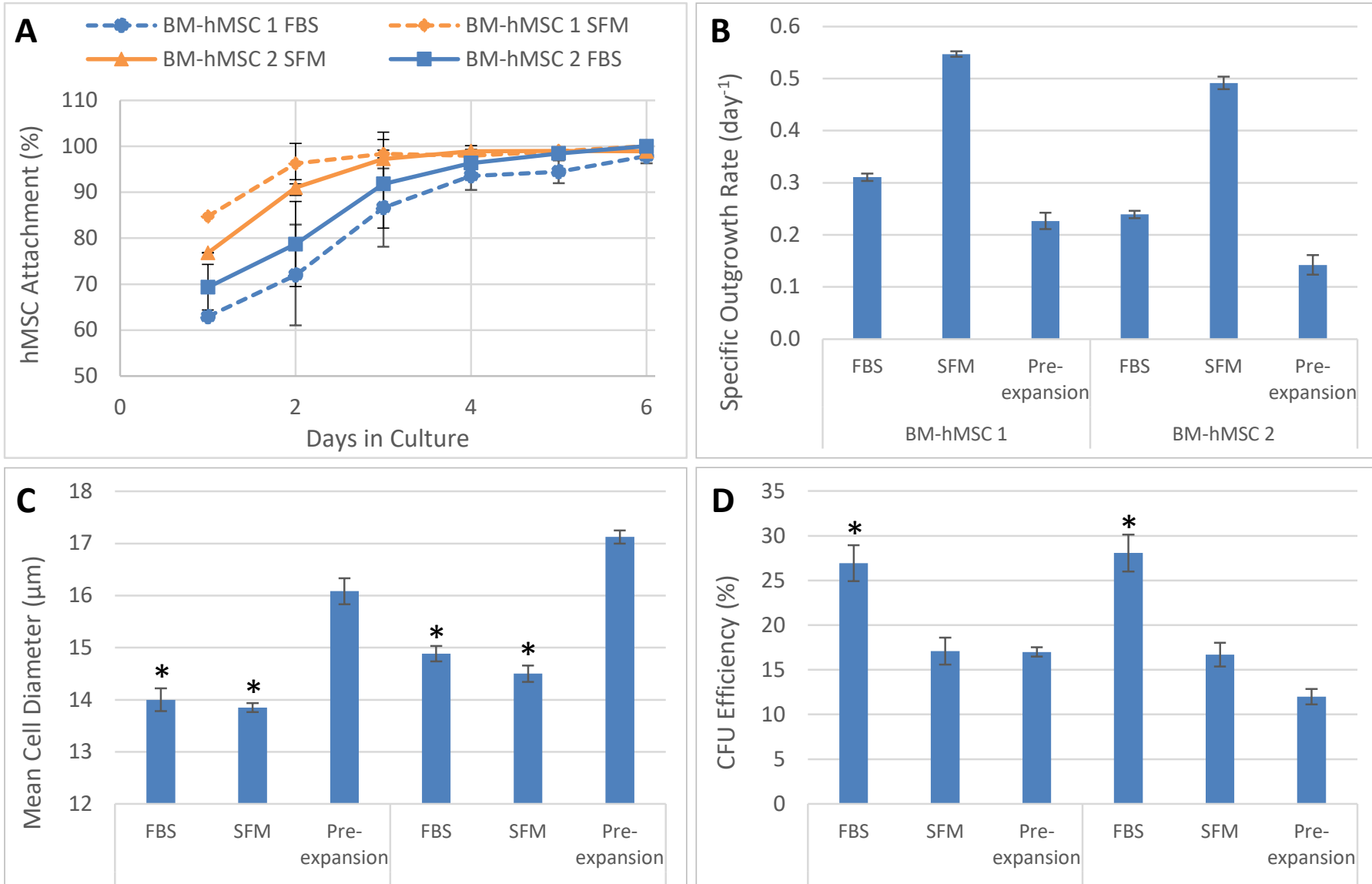

Figure 6 - Attachment rate and post-harvest characteristics during culture on microcarriers in the bioreactor in FBS and SFM across two BM-hMSC donors at $115 \mathrm{rpm}$, with controlled $25 \% \mathrm{dO}_{2}$ by headspace aeration and a $\mathrm{pH}$ of 7.4 . Showing $(A)$ increased cell attachment to microcarriers in SFM, (B) increased outgrowth rate in SFM, (C) reduced mean cell diameter and (D) maintained CFU efficiency post-harvest. Data shows mean $\pm S D, n=3$. ${ }^{*}$ denotes a significant difference $(p<0.05)$ compared with the same BM-hMSCs preexpansion. 


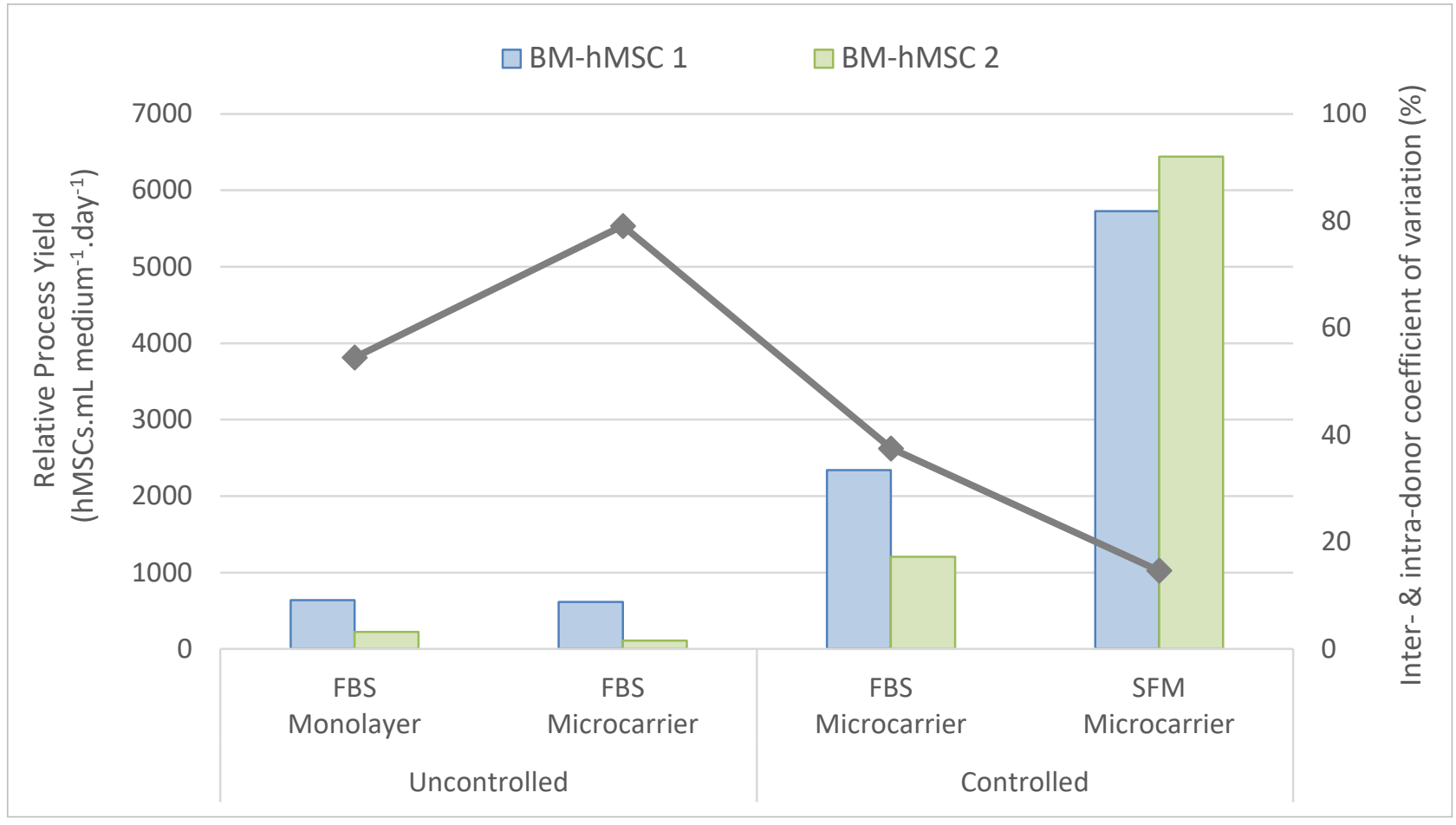

Figure 7 - Impact of process control on the process yield from a microcarrier expansion process at $25 \% \mathrm{dO}_{2}$ in the bioreactor compared poorly controlled monolayer and spinner flask culture under atmospheric conditions. Showing the controlled bioreactor process under serum-free conditions provides a much higher yield and more consistency between donors. Bars denote process yield in terms of number of cells produced per volume of medium per unit time and the line chart denotes the coefficient of variation between and within donor batch runs. 
Supplementary Figures 

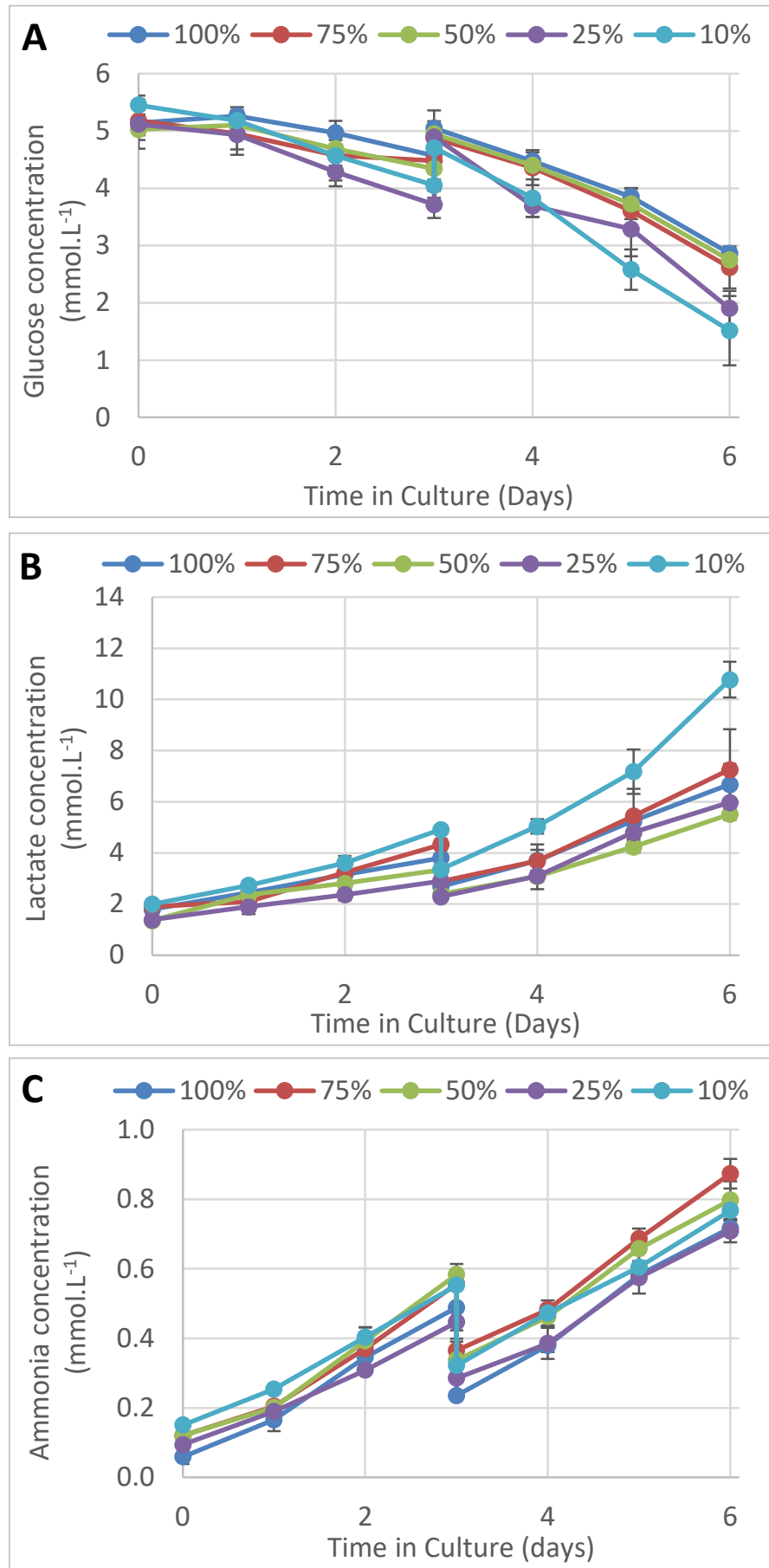

Supplementary figure 1 - Effect of $\mathrm{dO}_{2}$ on the live metabolite concentrations during BM-hMSC 1 expansion in FBS-containing medium in controlled microcarrier culture: (A) glucose; (B) lactate; (C) ammonia. Data shows mean $\pm S D, n=3$ 


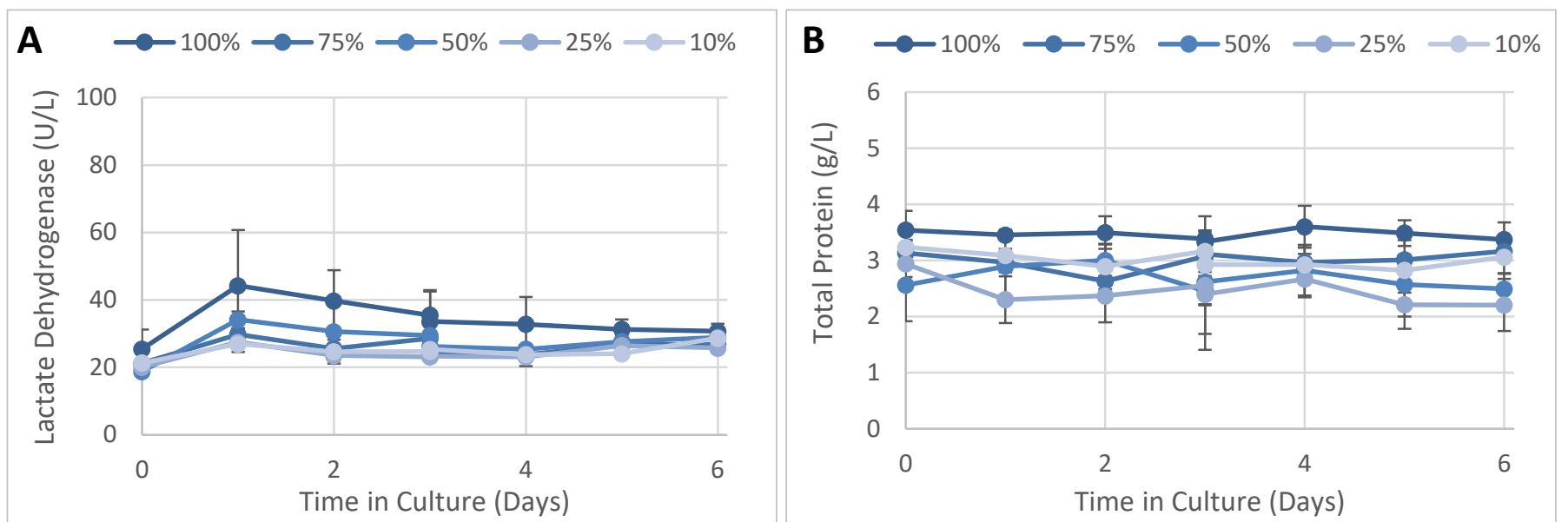

Supplementary figure 2 - Effect of $\mathrm{dO}_{2}$ on the metabolite flux of BM-hMSC 1 in FBS in controlled microcarrier culture: (A) LDH concentration; (B) total protein. Data shows mean $\pm S D, n=3$. 


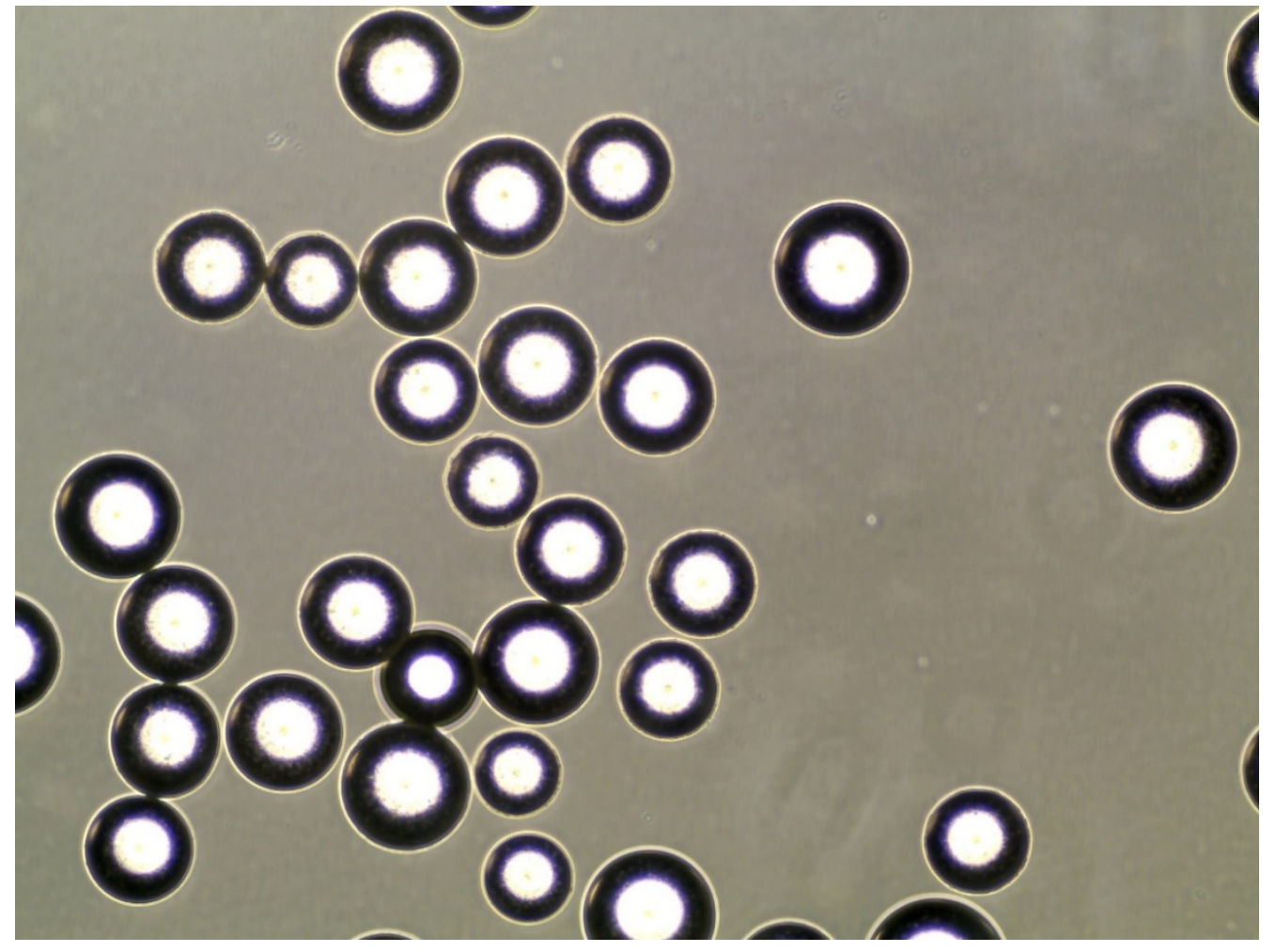

Supplementary figure 3 - Phase contrast image of microcarriers post-harvest from the SFM process. Demonstrating that the BM-hMSCs have been successfully removed from the microcarriers during the harvesting process. 

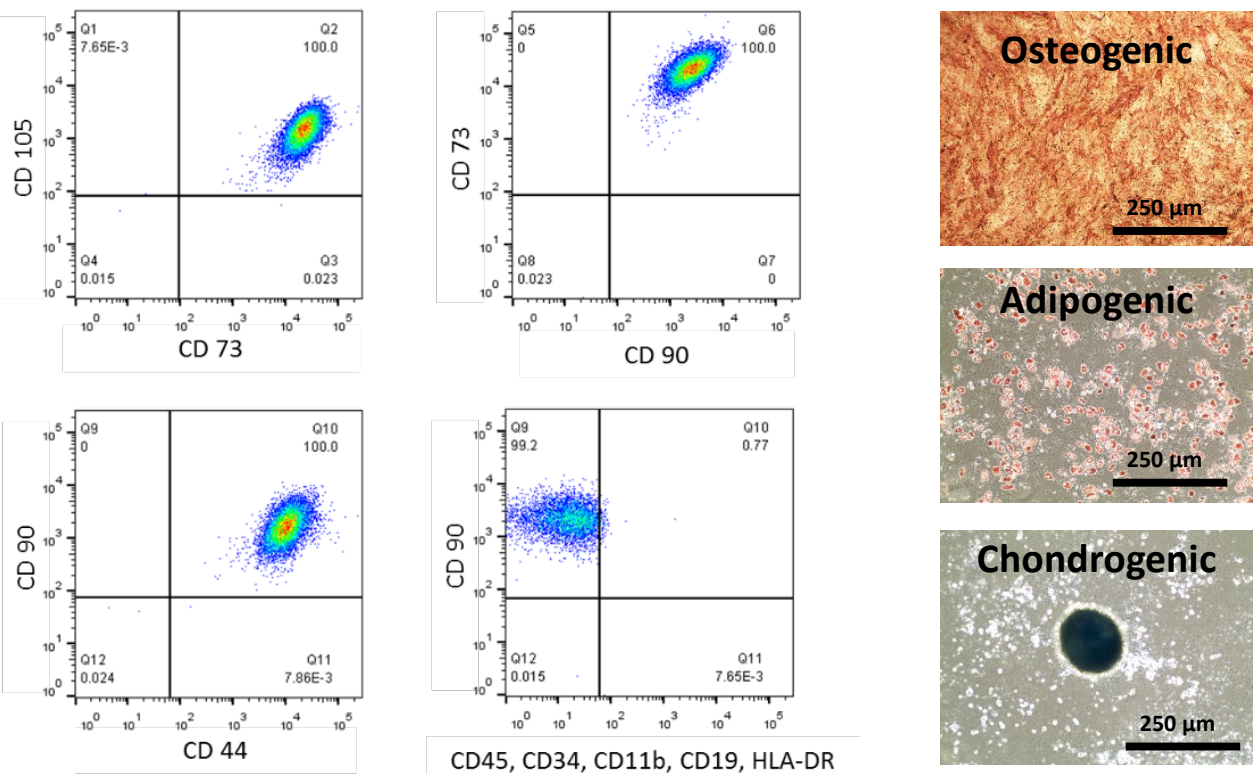

\% co-expression of immunophenotye markers

$$
\begin{aligned}
& 96.50 \pm 0.14 \\
& 96.80 \pm 0.28 \\
& 95.80 \pm 0.14
\end{aligned}
$$

Supplementary figure 4 - Verification of post-harvest immunophenotype and differential potential of BMhMSCs used during this study in accordance with the ISCT minimum criteria. 